\title{
An Overview on LNG Business and Future Prospect in Bangladesh
}

\author{
Saiful Islam, A. T. M. Shahidul Huqe Muzemder \\ Department of Petroleum \& Mining Engineering, Shahjalal University of Science and Technology, Sylhet, Bangladesh
}

Email address:

saifulpmre@gmail.com (S. Islam), shahidulpme@gmail.com (A. T. M. S. H. Muzemder)

\section{To cite this article:}

Saiful Islam, A. T. M. Shahidul Huqe Muzemder. An Overview on LNG Business and Future Prospect in Bangladesh. Science Journal of Energy Engineering. Vol. 3, No. 5, 2015, pp. 40-45. doi: 10.11648/j.sjee.20150305.11

\begin{abstract}
Bangladesh is characterized by both relatively high growth rates in population and expanding economies and a deficiency in domestic fossil fuel energy. Growing population and expanding economies are main causes of increasing energy demand. This study provides an overview of global liquefied natural gas (referred as LNG) technologies, business as it currently exist and examines the future potential growth in this market. In addition, this study examines the prospects for Bangladesh in this sector and the factor behind this potential entry. Over the last fifteen years, world trade in LNG is more than tripled and it is anticipated that this market will continue its rapid expansion with the technological development to meet the demand for energy. The current consumers of LNG are mainly to be found among the energy hungry economies of South East Asia as well as the western European countries. It also expected to exhibit the highest future growth rate, given the underlying economic growth of the countries found in this region and their burgeoning demand for energy. In Bangladesh, natural gas is the main source of energy that accounts for $75 \%$ of the commercial energy of the country. Most of the industries and power generation plants are driven by natural gas. Bangladesh currently produces about 2250 million cubic feet per day (mmcfd) natural gas with a shortage of about $450 \mathrm{mmcfd}$. To overcome this shortage initiative should be taken to find an alternative new source of energy such as- importing LNG, production of coal and renewable energy. For the immediate solution of this problem LNG would be good option but for long term solution all other options should take under consideration to secure the future demand of energy.
\end{abstract}

Keywords: LNG, Demand, Supply, Bangladesh

\section{Introduction}

The Liquefied Natural Gas (LNG) is natural gas in liquid state at atmospheric pressure and temperatures around $161^{\circ} \mathrm{C}$. The volume is reduced a factor 600times compared to the standard conditions, which allows larger volumes of LNG to transported by sea in refrigerated ships. In the last decades the world-wide LNG has growth significantly to meet the demand of natural gas allowing business opportunities.LNG plants have been designed for high capacities, base load plant, exceeding 150 million cubic feet per day(MCFD) of natural gas. The designs of large capacity LNG plants are focused mainly on the exploration of vast natural gas fields and towards the construction of major facilities, in order to take advantages of economies of scale. Different technologies for liquefying natural gas have been developed; being the most used the technologies of two and three cycles of cooling, with cascade or propane pre-cooling plus mixed refrigerant schemes. At present there are two major technology licensors which have dominated the LNG market for years.

The current consumers of LNG are mainly to be found among the energy hungry economies of South East Asia as well as the western European countries. It also expected to exhibit the highest future growth rate, given the underlying economic growth of the countries found in this region and their burgeoning demand for energy.

In Bangladesh, natural gas is the most important indigenous source of energy that accounts for $75 \%$ of the commercial energy of the country. So far 25 gas fields have been discovered of which two of the gas fields are located in offshore area. Currently gas is being produced from 20 gas fields. Oil was tested in two of the gas fields (Sylhet and Kailashtila). To reduce the dependency on natural gas, alternative energy resource including LNG must be explored. 


\subsection{Properties of Liquefied Natural Gas (LNG)}

LNG is the cleanest form of natural gas and contains more than $90 \%$ methane therefore, LNG becomes synonyms to methane. It is colorless, odorless, nontoxic and noncorrosive. Its weight is less than one-half that of water. Hazardous include flammability, freezing and asphyxia. The density of LNG is approximately $0.41-0.5 \mathrm{~kg} / \mathrm{L}$, depending on temperature, pressure and composition, compared to water at $1.0 \mathrm{Kg} / \mathrm{L}$. The heating value depends on the source of gas that is used and the process that is used to liquefy the gas. The higher heating value of $\mathrm{LNG}$ is estimated to be $24 \mathrm{MJ} / \mathrm{L}$ at $164{ }^{\circ} \mathrm{C}$. This value corresponds to a lower heating value of $21 \mathrm{MJ} / \mathrm{L}$. LNG is produced by cooling natural gas to $161{ }^{\circ} \mathrm{C}$ at which it becomes a liquid. This process reduce its volume by a factor of more than 600 similar to reducing the volume of a beach ball to the volume of a ping-pong ball. The ability to convert natural gas to $\mathrm{LNG}$, which can be shipped on specially built to ocean-going ships, provides consumers with access to vast natural gas resources worldwide.

\subsection{Global LNG Market}

Efforts to liquefy natural gas for storage began in the early 1900s, but it was not until 1959 that the world's first LNG ship carried cargoes from Louisiana to the United Kingdom, providing the feasibility of trains oceanic LNG transport. Five years later the United Kingdom began importing Algerian LNG, making the Algerian state-owned oil and gas company, Sonatrach, the world's first major LNG exporter. The United Kingdom continued to import LNG until 1990, when British North Sea gas became a less expensive alternative. [16].

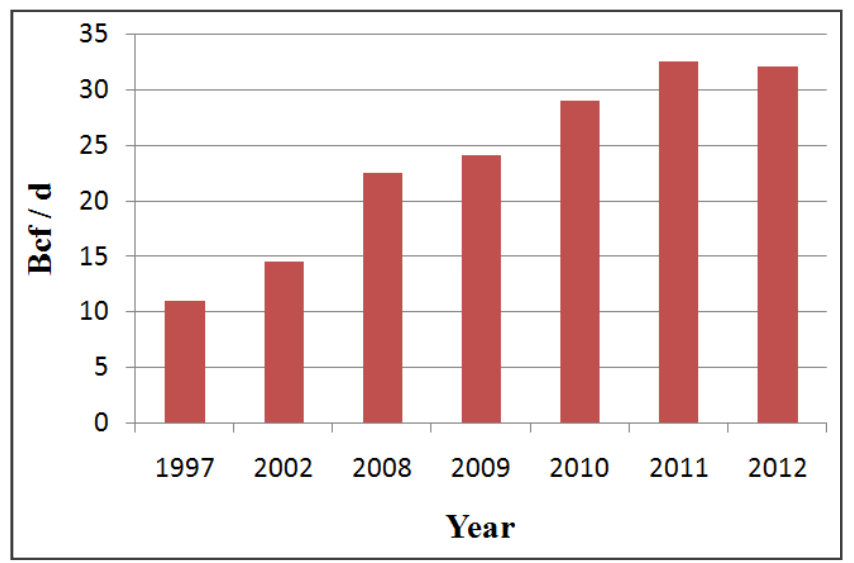

Figure 1. World LNG Trade. [source: EIA.OGJ, BP Statistical Review of World Energy].

Japan first imported LNG from Alaska in 1960 and moved to the forefront to the international LNG trade in the 1970s and 1980s with a heavy expansion of LNG imports. These imports into Japan helped to fuel natural gas fired power generation to reduce pollution and relieved pressure from the oil embargo of 1973. Japan currently imports more than 95 percent of its natural gas and as shown in Figure serve as the destination for about half the LNG exported worldwide.
World trade in LNG has grown dramatically over the last fifteen years. As shown in (figure9), trade in LNG more than tripled, growing from just over $10 \mathrm{Bcf} / \mathrm{d}$ in 1997 to $32 \mathrm{Bcf} / \mathrm{d}$ in 2012. It is anticipated that this market will continue its rapid expansion as better production technology means more gas reserves worldwide are available for development while demand for energy, particularly for those with cleanerburning properties, is expected to grow. [16].

\subsection{World LNG Supply}

The current suppliers of LNG to worlds markets and those that are expected to emerge as significant suppliers in the future come, not surprisingly, from those countries that are endowed with the largest natural gas reserves. Currently the countries located in Pacific Basin that supply the largest amounts of LNG include Malaysia, Indonesia and Australia (Table 1). Australia has a number of LNG liquefaction projects both under construction and in planning states, which should see it emerges as a much more significant supplier in future years. Also the first exports of LNG from Russia have occurred with the completion of its Shkhalin II project, which is Likely to be the first of several future LNG liquefaction developments in this country. [16]

Table 1. Global LNG Supply (BCF/D) [Source: Oil and Gas Journal and BP World Energy Statistical Review].

\begin{tabular}{lllll}
\hline Exporter & $\mathbf{2 0 0 9}$ & $\mathbf{2 0 1 0}$ & $\mathbf{2 0 1 1}$ & $\mathbf{2 0 1 2}$ \\
\hline Malaysia & 2.8 & 3 & 3.22 & 3.10 \\
Indonesia & 2.5 & 3 & 2.82 & 2.40 \\
Australia & 2.3 & 2.5 & 2.51 & 2.70 \\
Brunei & 0.9 & 0.8 & 0.91 & 0.90 \\
Russia & 0.7 & 1.3 & 1.39 & 1.40 \\
Alaska & 0.1 & 0.2 & 0.2 & 0.10 \\
Peru & 0 & 0 & 0.5 & 0.50 \\
Total Pacific Basin & 9.3 & 10.8 & 11.55 & 11.1 \\
Qatar & 4.8 & 7.3 & 9.92 & 10.20 \\
Oman & 1.2 & 1.1 & 1.06 & 1.10 \\
Abu Dhabi & .7 & .8 & 0.77 & 0.70 \\
Yemen & 0 & 0.5 & 0.86 & .70 \\
Total Middle East & 6.7 & 9.7 & 12.61 & 12.7 \\
Trinidad & 1.9 & 2 & 1.83 & 1.80 \\
Algeria & 2.1 & 1.9 & 1.66 & 1.50 \\
Nigeria & 1.5 & 2.3 & 2.5 & 2.60 \\
Egypt & 1.2 & 0.9 & .83 & .60 \\
Norway & 0.30 & 0.5 & 0.38 & 0.50 \\
Equatorial Guinea & 0.4 & 0.5 & 0.51 & 0.50 \\
Libya & 0.1 & 0.3 & 0.01 & 0.00 \\
Total Atlantic Basin & 7.5 & 8.4 & 7.72 & .5 \\
Total World & 23.5 & 28.8 & 31.88 & 31.30 \\
\hline
\end{tabular}

Of those countries located in and supplying markets in the Atlantic Basin, Trinidad, Algeria and Nigeria are currently the dominant suppliers. Nigeria, however have a number of LNG liquefaction projects being planned and developed that should increase its relative significance as an LNG supplier in years to come.

Exporters of LNG from the Middle East are dominated by those from Qatar, which is currently the largest exporter of LNG in the World. This status, however, could come under threat from Australia over the next decades as this country has a considerable number of $\mathrm{LNG}$ liquefaction projects 
being planned and developed LNG exports from the Middle East serve markets located in both the pacific and Atlantic basins. [16].

\subsection{World Demand for $L N G$}

The Energy Information Administration is expecting world-wide natural gas consumption to increase from 310 $\mathrm{Bcf} / \mathrm{d}$ in 2010 to $507 \mathrm{Bcf} / \mathrm{d}$ in 2040 Figure 11. Much of this increase is due to the anticipated growth in the use of natural gas for power generation as countries take advantage of cleaner burning properties of this fuel. Natural gas consumption is expected to grow considerably faster in developing countries, as the world wide use of natural gas increases, the size of the LNG market will grow as well. While currently about $10 \%$ of natural gas produced globally is liquefied, the LNG market will likely account for a growing share of world natural gas trade as worldwide liquefaction capacity increases. [16].

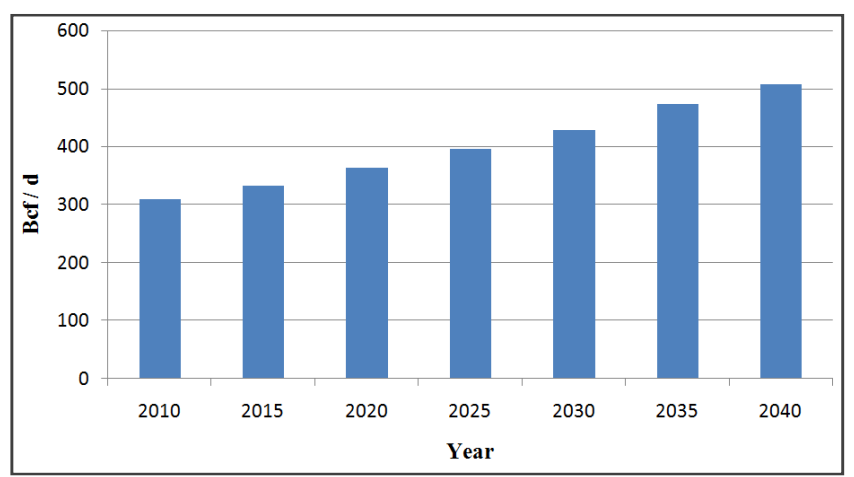

Figure 2. World Natural Gas Consumption [Source: EIA 2013 International Energy Outlook].

The current consumers of LNG are mainly to be found among the energy hungry economies of South Asia as well as a number of the more developed Western European countries. Some LNG is also imported into North and South America. The pacific Basin is the Largest Consuming region and is also expected to exhibit the highest future growth rate given the underlying economic growth of the countries found in this region and their burgeoning demand for energy. With respect to South East Asian importers of LNG, Table 2 shows that Japan is by far the largest importer in this region and in fact the whole world with more than 30 LNG import terminals currently in service and several more being planned. Japan currently accounts for over $35 \%$ of the entire world wide consumption of LNG and with substantial damage to Japanese nuclear power generating capacity as a result of the Tsunami that occurred in March 2011, LN G imports may grow higher in future to compensate the loss of nuclear power generating capacity. China has recently emerged as a net importer of natural gas. With its almost insatiable demand for Energy, it is expected to become a major importer of LNG in the future. India is also expected to increase its future demand for LNG.

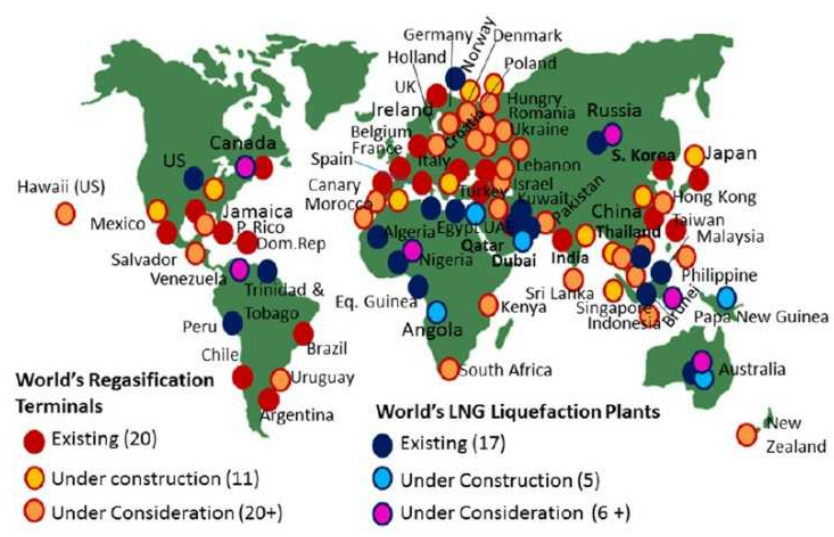

Figure 3. World's majorLNGexportingandimportingcountries. [Source: BGgroup].

The developed economies of Western Europe imported 6.6 $\mathrm{Bcf} / \mathrm{d}$ in2012, down from $8.7 \mathrm{Bcf} / \mathrm{d}$ in 2011 as economics of the region continue to struggle. These nations are not expected to increase their demand for the LNG anywhere near the same rate as the growing Asian economies. LNG is also consumed in America, but the emergence of shale and gas in North America means that this region is more likely to become a net exporter of LNG rather than an importer. [16].

Table 2. Imports of $L N G(B c f / d)$.

\begin{tabular}{lllll}
\hline Country & $\mathbf{2 0 0 9}$ & $\mathbf{2 0 1 0}$ & $\mathbf{2 0 1 1}$ & $\mathbf{2 0 1 2}$ \\
\hline France & 1.26 & 1.34 & 1.41 & 1 \\
Spain & 2.56 & 2.66 & 2.34 & 2.1 \\
Portugal & 0.29 & 0.3 & 0.3 & 0.4 \\
Turkey & 0.54 & 0.77 & 0.6 & 0 \\
Belgium & 0.62 & 0.63 & 0.64 & 0.4 \\
Italy & 0.27 & 0.88 & 0.85 & 0.7 \\
Greece & 0.08 & 0.11 & 0.13 & 0 \\
UK & 1.02 & 1.81 & 2.45 & 1.3 \\
US & 1.2 & 1.18 & 0.97 & 0.5 \\
Puetro Rico & 0.07 & 0.08 & 0.07 & 0 \\
Dom. Republic & 0.05 & 0.08 & 0.09 & 0 \\
Mexico & 0.34 & 0.55 & 0.39 & 0.5 \\
Brazil & 0.07 & 0.27 & 0.1 & 0.3 \\
Argentina & 0.09 & 0.16 & 0.42 & 0.5 \\
Chile & 0.06 & 0.3 & 0.37 & 0.4 \\
Canada & 0.08 & 0.19 & 0.32 & 0.2 \\
Kuwait \& United Arab Emirates & 0.09 & 0.27 & 0.43 & 0.4 \\
Total Atlantic Basin \& America & 8.771 & 11.59 & 11.88 & 9.4 \\
Japan & 8.39 & 9.04 & 10.34 & 11.5 \\
South Korea & 3.36 & 4.3 & 4.77 & 4.8 \\
Taiwan & 1.07 & 1.45 & 1.58 & 1.6 \\
India & 1.18 & 1.18 & 1.65 & 2 \\
China & 0.72 & 1.23 & 1.61 & 1.9 \\
Total Pacific Basin & 14.71 & 17.21 & 19.95 & 21.8 \\
World Total & 23.42 & 28.79 & 31.83 & 31.2 \\
\hline
\end{tabular}

[Source: Oil and Gas Journal and BP World Energy Statistical Review]

\subsection{Future Prospect of LNG in Bangladesh}

In Bangladesh, natural gas is the most important indigenous source of energy that accounts for $75 \%$ of the commercial energy of the country. So far 25 gas fields have been discovered of which two of the gas fields are located in offshore area. Currently gas is being produced from 20 gas fields. Oil was tested in two of the gas fields (Sylhet and 
Kailashtila). To reduce the dependency on natural gas, alternative energy resource must be explored.

\subsection{Current Scenario of Gas Sector in Bangladesh}

The main source of energy of Bangladesh is indigenous natural gas and imported petroleum. At present, daily average gas production is about 2300-2350 mmcf. National Gas companies' produces around 1050-1100 mmcf (42\%) and the IOCs produces around 1200-1300 mmcf (58\%),off the total production of gas, presently used in Power sector, Fertilizer, Captive Electricity, Industry, CNG, Commercial, Tea Gardens and in Domestic sector (Figure12).

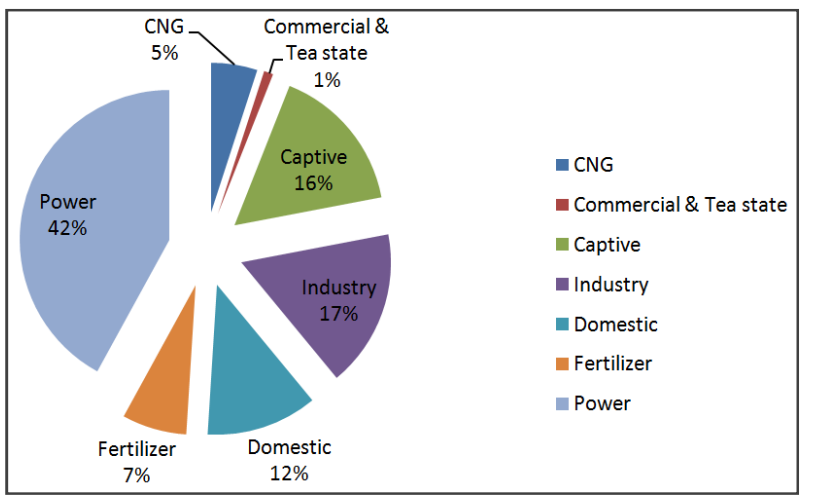

Figure 4. Gas consumption sectors in 2012. [source: Annual Report-2012, Petrobangla].

As per official statistics, there is a suppressed demand of around 500-700 mmcfd of gas. If gas was made available, may be at this time it would have exceeded daily usage of 4000 mmcf. Moreover, during the last few years, gas transmission pipeline has been extended up to Khulna and Rajshahi. When those areas would be brought under fullfledged gas supply without making available sufficient sources of supply, it would be a real difficult situation in maintaining supply to the present consumers what to talk about supplying new customers of the new areas. Therefore, an alternative has to be in place before actual supply starts in the new areas. The only alternative to make available natural gas is import of gas or discovery of a gas reserve like Titas or Bibiyana fields. The means of import of gas is pipe gas or it could be LNG. [15].

\subsection{LNG for Bangladesh}

Now a days, to meet immediate requirement of natural gas, importing LNG is the main source of supply. The government also took the initiative in 2010 and a delegation headed by the Secretary, Energy visited Qatar in June 2010 and agreed a Memorandum of Understanding which was signed in January 2011. In short term solution various countries adopting the methodology of Floating Storage \& Re-gasification Unit (FSRU) instead of land based permanent type. However, considering the cost effectiveness, with the short term solutions one should not forget about the landbased LNG facilities. In Bangladesh, as the port facilities is very limited and specially for LNG vessel because of the higher requirement of draught, it has been planned to use FSRU near Moheshkhali where required draught is available at about 5-6 km offshore of Moheshkhali coast. The mother vessel carrying LNG would be transferred to the FSRU which would be moored at about $5-6 \mathrm{~km}$ off-coast of Moheshkhali. An offshore pipeline would be installed from the FSRU and a delivery point will be stationed on-shore at Moheshkhali Island. From the delivery point, a gas transmission pipeline of about $85-90 \mathrm{~km}$ would be installed to bring the gas at the port city of Chittagong. In Chittagong, it would be hooked up with Karnaphully gas system and the gas would be supplied to the customers. As per plan, initially about 500 mmcfd of gas would be supplied for which in total about 4 million ton of LNG would be required annually. [18]

\section{Basic Issues of LNG}

\subsection{Import of LNG \& LNG Handling Facilities}

The first and foremost requirement of handling LNG vessels is the availability of minimum 15 meter draught. Generally maximum draught available in Chittagong port is 10-12 meter which depends on the tide again. A vessel carrying 30,000 M.Ton of oil could not come to the unloading jetties and need to do lighterage of 10,000 M.Ton and then bring the vessel to the unloading jetties. Draught of 15 meter plus is available in and around 5-6 km off-coast of Moheshkhali. Therefore, to handle LNG vessel an adverse and tough situation had to be faced. As land based LNG terminal installation is not possible, there is no flexibility of choices but to go for FSRU type facilities. The FSRU is nothing but a LNG carrier having re-gasification process facilities on it. The mother vessels would come to the FSRU and transfer the LNG and the FSRU process and converts the LNG into gas and send it to the pipeline. In our case, from the FSRU, offshore pipeline of about 5-6 km would be needed and then from the onshore receiving station gas had to be brought to Chittagong area by connecting a pipeline of about $85-90 \mathrm{~km}$ of appropriate size. Again the underwater current situation of that area needs to be evaluated before installation of offshore pipeline for which bathometry study had to be conducted. As Bangladesh has not handled LNG vessel before, therefore, it is very crucial to know the methodology of handling the mother vessel and guide the mother vessel to the FSRU. Ship to Ship transfer of LNG is another crucial aspect of handling LNG. For all these Bangladesh need to create appropriate technical manpower and those persons need to be trained also. In area like Melaka Straight of Malaysia, it looks like big lake where there is hardly any high wave. In Kuwait, the sea is calm and quiet, and even the Break water can be seen from a distance. But think about the Bay of Bengal in Kutubdia / Moheshkhali Island area. The roughness of the sea especially during monsoon season may cause very difficult situation for handling LNG vessels. So one can easily understand the magnitude of activities involved in handling LNG in our situation. In 
Chittagong areas almost every year during monsoon season, we have cyclone and tornedos. Therefore, maintaining the continuous supply of LNG would be a challenging affairs and alternatives arrangement must be in place during such a situation to maintain the chain of continuous supply of LNG. [18].

\subsection{Price of $L N G$}

Another basic issue of LNG operation would be the price factor. Gas is already underpriced in our country as it is considered coming from indigenous sources. Presently, in the domestic producer level, three price regimes are existing. First, gas price of Bangladesh Gas Fields Company Limited (BGFCL) and Sylhet Gas Fields Limited (SGFL); second, gas price of Bangladesh Petroleum Exploration \& Production Company Limited (BAPEX); and third the gas price of IOCs (International Oil Companies). When import of LNG will start, another price factor would be added. Therefore, a suitable price mechanism needs to be in place so that LNG can be imported on uninterrupted basis. One might argue that present LNG price is tagged with oil price and it would be very costly for Bangladesh to effort. In this respect, according to a businessman of the country who said that instead of keeping the factories or mills in shutdown condition, if the factory can run with higher priced gas, there will be employment opportunity as well as the loan money from the bank which is presently yielding no output resulting non-payment of bank loan, at least it can be returned or process of returning the loan would start. If consider with broader sense and not confining within the issue of price, ultimately country would be benefitted. However, it must be kept in mind that 4 million ton of LNG means about minimum 6 billion dollar plus annually considering the present trend of price of LNG. [18].

\section{Long Term Vision for Bangladesh}

To start with importing of LNG by Bangladeshi, FSRU seems to be alright. Installation of FSRU and brining the gas into the system would take minimum 24-30 months. Now FSRU is not a proprietary to a particular supplier. While selecting FSRU, an in-depth understanding is required and all out efforts has to be there to minimize the cost as much as possible. Therefore, selection of size of FSRU is very important. Again it must be kept in mind the size of mother vessel of LNG. FSRU of 170,000-175,000 CBM can easily handle full standard size of LNG cargo and it would provide increased security of supply of LNG.A smaller FSRU size can also handle LNG but the flexibility/security would be limited. To meet the ever increasing demand of natural gas, we must plan for a permanent solution and that is installing a land based LNG facilities. Because of the draught restriction, a normal cargo vessel or oil tanker of 30,000 M.Ton cannot come to the port facilities of Chittagong. Government has already initiated "Deep Sea Port Project". It would be appropriate to include LNG facilities with the Deep Sea Port project so that permanent LNG facilities could be installed in due course of time. The main intention would be to reduce costing of LNG and its facilities. Very recently Singapore has taken an initiative to become a LNG hub like Oil hub. As Bangladesh would be signing contract with Qatar for import of LNG on long term basis, it may keep in mind the development of LNG facilities around Bangladesh so that it can take advantage as and when possible. Now in USA, LNG is sold at much lower price than Asia. So importing of LNG from USA may also be kept in mind. Another source of importing LNG may be Australia too. All these options had to be kept open while engaging import of LNG. [18].

\section{Discussion}

There is a widening gap between the amount of gas supplies available and the growing demand for natural gas. There are a lot of industrial units exists in the country which just cannot go into operation in the absence of gas. To meet this demand it is time think about alternative energy sources like LNG, coal and renewable energy, but to meet immediate requirement of natural gas, importing $\mathrm{LNG}$ is the main source of supply as Bangladesh has port facilities. One might argue that present LNG price is tagged with oil price and it would be very costly for Bangladesh to effort. Therefore, a suitable price mechanism needs to be in place so that LNG can be imported on an uninterrupted basis. Finally, it can be said that for the long term solution of the energy crisis in Bangladesh proper step should be taken to reduce the dependency of natural gas in power generation sector where most of the gases are used instead of that coal based plant should be developed.

\section{Conclusion}

Currently, there are different technological options with the potential to be applied in future LNG developments. These alternative technologies are mainly made up of two and three cycles of cooling, with schemes either cascading process or more pre-cooling with propane plus mixed refrigerants. However, the selection of liquefaction natural gas technology most appropriate depends on the priorities and conditions for each project.

The current consumers of LNG are mainly to be found among the energy hungry economies of South East Asia as well as the western European countries. It also expected to exhibit the highest future growth rate, given the underlying economic growth of the countries found in this region and their burgeoning demand for energy. Bangladesh is also thinking about LNG option to meet the demand of natural gas.

In the last decades the world-wide LNG has growth significantly to meet the demand of natural gas allowing business opportunities. It also expected that this market will continue its rapid expansion as better technologies are available. 


\section{References}

[1] Vink, K.J. and Nagelvoort, R.K. 1998. Comparison of Baseload Liquefaction Processes, Paper presented at the 1998 Intl. Conference on Liquefied Natural Gas, Perth, Australia, 4-7 May.

[2] Process Evaluation-Research Planning, Liquefied Natural Gas. PERP report by Chem systems Inc, 96/97S2, November.

[3] M.J. Roberrts, J. C. Bronfenbrenner, Yu-Nan Liju - Large Capacity Single Train AP-X Hybride LNG Process- Gastech 2012 Qatar.

[4] R. Nibbelke, S. Kauffman B. Pek - Liquefaction Process Comparison of C3MR and DMR for Tropical ConditionsGPA $81^{1 \mathrm{st}}$ annual convention, 2002.

[5] Chabrelie Marie F. LNG the way ahead. En: Fundamentals of the global LNG Industry, pp. 10-14, Londries: Petroleum Economist, 2007.

[6] Coll, Roberto; Carbon, Eudardo; Technology Evaluation Methodology for standard Gas Monetization Options, $19^{\text {th }}$ WPC, $29^{\text {th }}$ June- $3^{\text {rd }}$ July, Madrid, 2008.

[7] H. Bauer - A Novel Concept for Large LNG Basehold PlantsAICHE Spring National Meeting, 2001.

[8] Guerrero, Ramiro A. y otors. Processes of liquefied natural gas -state of the art. Caracas Universidad Simon Boliver, 2006.

[9] Nexant LNG: the Expanding Horizons of Liquefaction Technology and Project Execution Strategies. Houston: Nexant, 2007.

[10] PEK B, y otors. Large capacity LNG Plant development. LNG $14,2014$.

[11] Sang gyu Lee, Kun hyung Choe, Young Yang, The state of art LNG Liquefaction Plant Technologies, The $3^{\text {rd }}$ Korean Congress of refrigeration, vol. 3, pp.65-68. 2009.
[12] Seung Taek Oh, Ho Saeng Lee, Jumg In Yoon, Sang Gyu Lee, Development of LNG.

[13] Liquefaction Process, Journal of the SAREK, Vol. 38, No. 3, PP 13-17, 2009.

[14] Annual Report of Petrobangla-2012. $<$ http://energy.gov/sites/prod/files/2013/04/f0/LNG primerup d.pdf $>$.

[15] Report on "An Overview of the World LNG Market and CANADA's Potential for exports of LNG", January 2014 $<$ http://www.capp.ca/getdoc.aspx?DocId=237161\&DT=NTV $>$ (Accesed19 August 2014).

[16] Wikipedia, Liquefied Natural Gas, (22 August 2014 revision) $<$ http://en.wikipedia.org/wiki/Liquefied_natural_gas $>$ (Accessed 19 August 2014).

[17] Petrowiki, Liquefied Natural Gas, (23 March 2014 revision) $<$ http://petrowiki.org/Liquified_natural_gas_(LNG)> (Accessed 18 August 2014).

[18] <http://ep-bd.com/online/details.php?cid=32\&id=17538> (Accessed 20 August 2014).

[19] BG Group, Aworldleader in natural gas. <http://www.bggroup.com/OurBusiness/BusinessSegments/Pages/pgLiquefie dNaturalGas.aspx.>.

[20] A. B. Raheem, A. Hassan, S. A. Samsudin, Z. Z. Noor, A. Adebobajo, Comparative Economic Investigation Options for Liquefied Petroleum Gas Production from Natural Gas Liquids, American Journal of Chemical Engineering. Special Issue: Developments in Petroleum Refining and Petrochemical Sector of the Oil and Gas Industry. Vol. 3, No. 2-1, 2015, pp. 55-69.

[21] Md. Niaz Murshed Chowdhury, Samim Uddin, Sumaiya Saleh. Present Scenario of Renewable and Non-Renewable Resources in Bangladesh: A Compact Analysis. International Journal of Sustainable and Green Energy. Vol. 3, No. 6, 2014, pp. 164-178. 